\title{
EFFECTIVENESS OF MASTITIS DETECTION INDEX FOR COW MONITORING AND ABNORMAL MILK DETECTION IN MILKING ROBOTS
}

\author{
Ivars Lusis, Vita Antane, Armins Laurs \\ Latvia University of Agriculture \\ ivars.lusis@1lu.lv, vita.antane@llu.lv
}

\begin{abstract}
The aim of the study was to evaluate the effectiveness of the Mastitis Detection index (MDi) for detection of cows with a high somatic cell count (SCC) during milking in the milking box of the DeLaval milking robot. The MDi takes conductivity, milking intervals and blood presence into consideration. All these factors and SCC dynamics were analyzed in 20 cows during a three-week period. The MDi was compared between the experimental group (cows with initial MDi 1.4 or more, $n=10$ ) with the control group (cows with initial MDi from 1.0 to $1.3, n=10$ ). Results have indicated that the MDi and milk conductivity in the experimental group were significantly $(p<0.05)$ higher compared with the control group cows (mean (SD) $1.40(0.29)$ vs $1.06(0.06)$ and $4634(469.4)$ vs $\left.4562(366.9) \mu \mathrm{S} \cdot \mathrm{cm}^{-1}\right)$. There were significantly longer milking intervals (12 hours and more), and consequently less number of the milking sessions per day in the experimental group $(2.3(0.74)$ vs $2.6(0.72) \quad(p<0.05)$. In total, the experimental group has significantly higher $\log _{2}$ SCC 3.4 (1.53) vs 2.4 (1.45). To characterize the overall effectiveness of the MDi for detection of cows with SCC above 200000 cells ml $^{-1}$ of milk the Cohen`s kappa from 430 milking sessions were calculated and the agreement was found to be less than moderate (kappa $=0.28 \pm 0.048$ ). Besides that, the threshold values of the MDi for automatic divert of abnormal milk were modeled. If the threshold is set as high as 2.0, the SCC of diverted milk would be around 422000 cells $\mathrm{ml}^{-1}$ and total amount of diverted milk would be $2.3 \%$ of all milk production. At the same time, the bulk tank SCC would be as low as $155000 \mathrm{cells} \cdot \mathrm{ml}^{-1}$. Any lover threshold would increase the amount of diverted milk, however, the somatic cell count in the bulk tank would decrease even lower.
\end{abstract}

Keywords: milking robot, mastitis detection, abnormal milk.

\section{Introduction}

Mastitis detection and divert of abnormal milk is an everyday practice on milk producing farms, including modern farms with milking robots. By using milking robots people do not control health of every animal at every milking, therefore on-line measurements and indicators are of high value. Different international companies represented in Latvia (DeLaval, GEA, Lely) have implemented in their milking robots a set of milk quality and quantity parameters. In case of departure from normal values, a trigger is registered in the herd management system. At the milking robots, on-line measurements of a quarter level milk electrical conductivity (EC), blood presence and milk yield from every quarter are registered as well. Decreased milk volume could be caused by incomplete milking, kick-off or health disturbances, including mastitis. Somatic cell count (SCC) is a well known parameter and also used at a quarter level in automatic milking systems (AMS, Lely) and at udder level in the voluntary milking system (VMS, DeLaval) in case it is equipped with Online Cell Counter (OCC). A less known udder level parameter is the mastitis detection index (MDi) taking into consideration three parameters, namely conductivity, milking interval and blood presence at a quarter level. There is no evidence about research on effectiveness of MDi and no comparison with SCC. At present, basic information about this index could be found only in the users' manual of the milking system VMS. The MDi could be in the range from 0.8 to 4.0 and if it is under 1.4 the probability of a cow to get health problems is regarded as low. The MDi value above 2.0 indicates that the cow needs immediate attention of the farmer. There is no exact scientific evidence of MDi level for abnormal milk; the farmers should set this borderline themselves empirically.

Theoretically (presentation for VMS users "Cow Monitoring in VMS", DeLaval, 2009), the MDi is a good parameter for healthy cows, which are suspected to develop clinical mastitis in the near future. It means that changes in milk are detected before the clinical mastitis; therefore, the aim of the study was to evaluate the importance of this index also for the diagnostics of subclinical mastitis and detection of abnormal milk.

\section{Materials and methods}

The research was carried out on the dairy farm where the milking robot Voluntary Milking System (VMS, DeLaval) has been implemented in a group of 60 cows on average. On-line 
measurements of milk conductivity, blood presence, milk yield at a quarter level and somatic cell count from OCC at a cow level were obtained. Earlier research showed [1] that the milking robot OCC diagnostic device accurately finds cows with a high SCC (> $\left.200000 \mathrm{cells} \cdot \mathrm{ml}^{-1}\right)$. Additionally, milking intervals and milking sessions per day were registered. Data were collected in the management system and obtained from the milking robot backup filed information during a three-week period in October 2010. As the MDi was actualized at every milking and the previous values were not stored, it was necessary to follow and save screenshots once every day in order to keep track of actual dynamics of the MDi. All cows with the initial MDi $\geq 1.4$ were classified as experimental group $(n=10)$. Control group $(n=10)$ had been randomly selected from other cows with the initial MDi from 1.0 to 1.3. During the experiment, a quarter level analysis of SCC was performed two times by the fluoro-opto electronic reference method (automatic analyser Somacount 300) at accredited dairy laboratory.

The research data were registered and analyzed with software STATA 12.0. Dinamics of the MDi were summarized by the ANOVA method for repeated measurements. Differences between the groups were considered significant if $p<0.05$ throughout the study.

\section{Results and discussion}

During 21 days, 942 milking sessions in total were registered in 20 cows. The MDi result was obtained in 522 milking sessions. Each cow was milked on average $2.1(0.71)$ times a day in the experimental group in comparison with $2.4(0.68)$ in the control group. No clinical mastitis was observed. Cows were selected from the milking robot group according to the MDi value observed at the start of a three-week period. The results of MDi in the experimental group and control group are shown in Fig. 1.

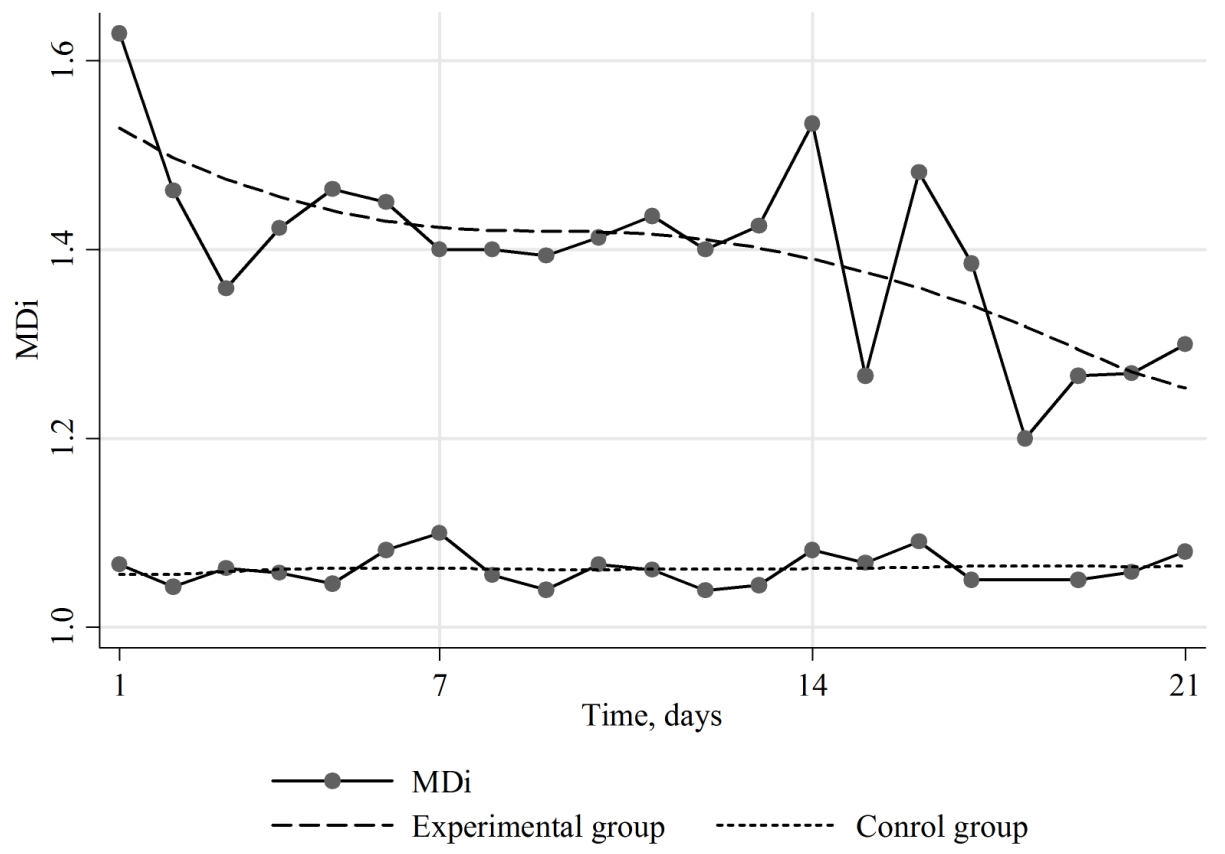

Fig. 1. Mastitis detection index (MDi) in the experimental and control group

Mean MDi values in the experimental group are constantly higher than in the control group. During a three week-period the MDi level in the experimental group was gradually decreasing (linear regression coefficient $-0.01, p<0.05$ ). The total decrease was 0.2 over the whole three weeks. However, the experimental group cows do not reach the low level of MDi that was in the control group. The mean MDi of the experimental group cows remained elevated above 1.4 for two weeks, allowing to make the assumption about biological changes in the udder or in the cows body as a whole. After those two weeks it arrived at the normal level below 1.4. That probably shows the onset of recovery, however, according to Lukas [2], more controlled studies including milk bacteriology would be necessary to substantiate such a conclusion.

Fig. 1 shows evidence that the variation of MDi is much greater in the experimental group than in the control group. Especially, around the beginning of the third week of the experiment, dynamic 
patterns of mean MDi are similar in both groups. Although, with a markedly greater range in the experimental group.

Analysis of individual MDi values for the experimental group cows showed that several high MDi values above 1.4 had been detected during the study period. Whereas in control cows the values of 1.0 and 1.1 dominated throughout the whole study period.

There are three quarter level parameters joined together in MDi calculation - blood presence in milk, milking interval and electrical conductivity of milk. No blood was observed in milk, only subclinical mastitis was present during the study period. It suggests that only electrical conductivity or a prolonged milking interval could be the reason of MDi increase.

Fig. 2 shows a relatively higher proportion of long milking intervals (12 hours and more) in the experimental group $(47.5 \%)$ than in the control group $(23.8 \%)$. Most of milking intervals $(62.8 \%)$ in the control group were of moderate length ranging from 8 to 12 hours and resembling mean milking frequency across our study 2.3 (0.71) times a day. Milking sessions proceeded by short intervals 4 to 8 hours not more than $10 \%$ in both groups. Experimental group had significantly longer milking intervals and less milking sessions per day because days in milk of experimental cows were higher (335 (134.4) compared to the control group 197 (118.8).

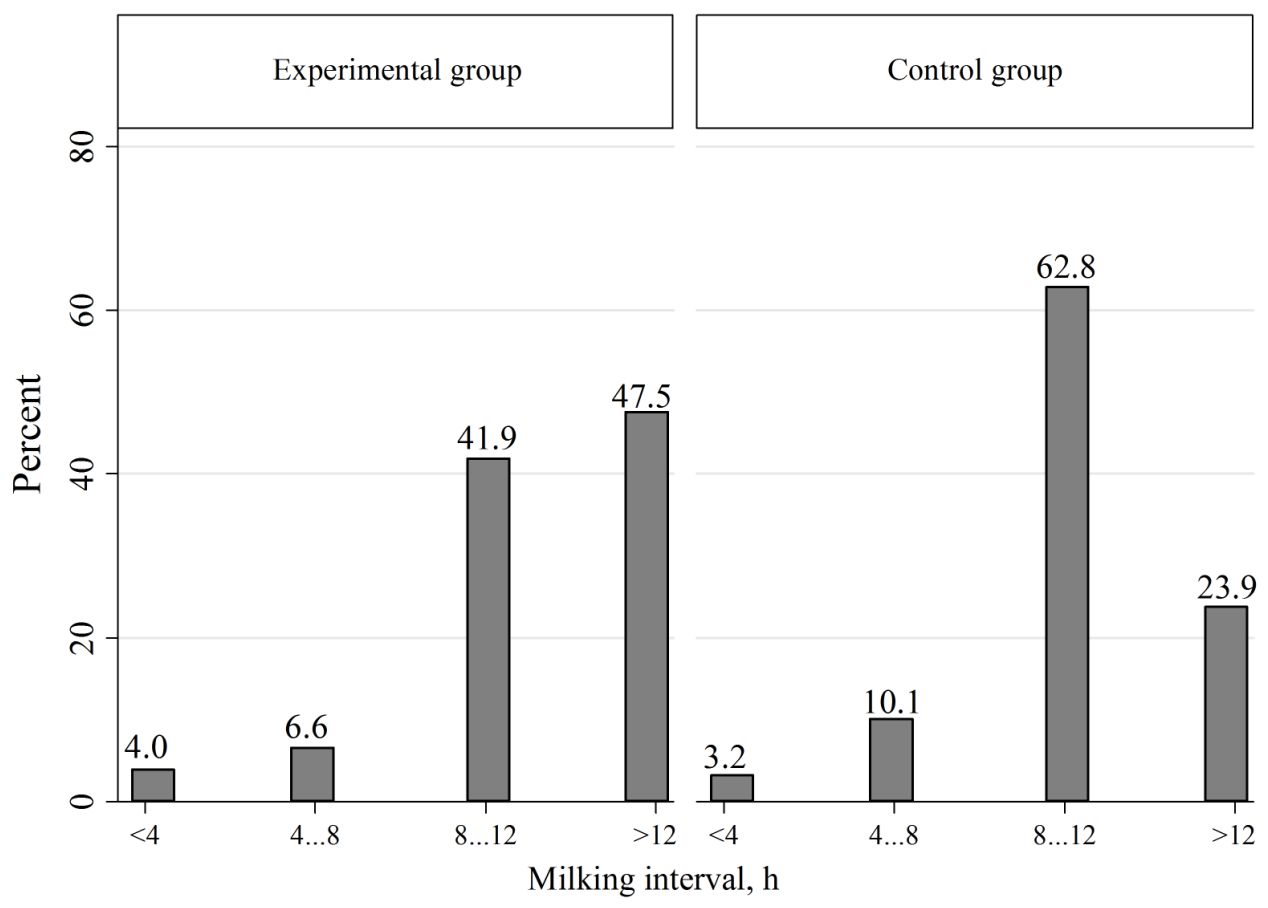

Fig. 2. Distribution of milking intervals in the study groups

Concerning EC, mean values between the experimental and control group were compared in Table 1. Mean value of a cow level EC in the experimental group was significantly higher than in the control group $\left(4634 \mu \mathrm{S} \cdot \mathrm{cm}^{-1}\right.$ and $4562 \mu \mathrm{S} \cdot \mathrm{cm}^{-1}, p<0.05$, respectively). However, both results were under mean EC values of healthy $\left(5.3 \mathrm{mS} \cdot \mathrm{cm}^{-1}\right)$ and subclinically infected cows $\left(5.7 \mathrm{mS} \cdot \mathrm{cm}^{-1}\right)$ as reported by Norberg et al. [3].

Table 1

Electrical conductivity of milk in cows grouped by MDi in automated milking

\begin{tabular}{|c|c|c|c|c|c|}
\hline Group & Initial MDi & $\begin{array}{c}\text { Number of } \\
\text { cows }\end{array}$ & $\begin{array}{c}\text { Number of } \\
\text { milking } \\
\text { sessions }\end{array}$ & $\begin{array}{c}\text { Mean MDi } \\
\text { (SD), } \\
\boldsymbol{\mu S} \cdot \mathbf{c m}^{-1}\end{array}$ & $\begin{array}{c}\text { Significant } \\
\text { difference } \\
\text { from control }\end{array}$ \\
\hline Experimental & $\geq 1.4$ & 10 & 437 & $4634(469.4)$ & $p<0.05$ \\
\hline Control & $<1.4$ & 10 & 505 & $4562(366.9)$ & - \\
\hline Total & - & 20 & 942 & $4595(418.9)$ & - \\
\hline
\end{tabular}


However, a quarter level $\mathrm{EC}$ was above $5700 \mu \mathrm{S} \mathrm{cm}^{-1}$ only at 14 milking sessions out of $437(3.2 \%)$ in five experimental cows, but no cases were registered in control cows. All cows with a high quarter level EC had an elevated MDi above 1.4.

Further analysis of the present study was performed to look for any MDi association with SCC as a very important and well known parameter, a standard method for diagnosis of subclinical mastitis and milk quality [4-6]. In total, the experimental group had a significantly higher $\log _{2} \mathrm{SCC}(3.4$ (1.53) vs $2.4(1.45)$ ). Also, individual cow data showed that most often (12 of 20,60\%) higher MDi was associated with SCC above 200000 cells $\cdot \mathrm{ml}^{-1}$ during the study. However, in general correlation between the $\mathrm{MDi}$ and $\log _{2} \mathrm{SCC}$ was poor $(r=0.37, p<0.05)$. It could be explained by strong disagreement between these two measures in some individual cows, for example, experiment group cow No 7484 shown in Fig.3. This cow had high MDi values from 1.5 to 2.1 during the whole length of the experiment and SCC permanently below $100000 \mathrm{cells} \cdot \mathrm{ml}^{-1}$ measured by OCC on regular basis and once per month at accredited dairy laboratory. Long milking intervals (from 13 to 15 hours) often observed for that cow was probably the main reason for high MDi values. On the opposite, control group cow No 7375 shown in Fig.4 had permanently low MDi and high SCC at repeated occasions. To characterize overall effectiveness of the MDi for detection of cows with SCC above 200000 cells $\mathrm{ml}$ of milk the Cohen`s kappa from 430 milking sessions were calculated and agreement was found to be less than moderate (kappa $=0.28 \pm 0.048$ ). It shows that the changes in the MDi and somatic cell count are not in parallel. However, the increase of the MDi does not exclude association with the biological changes in the udder or throughout the animal body [7].

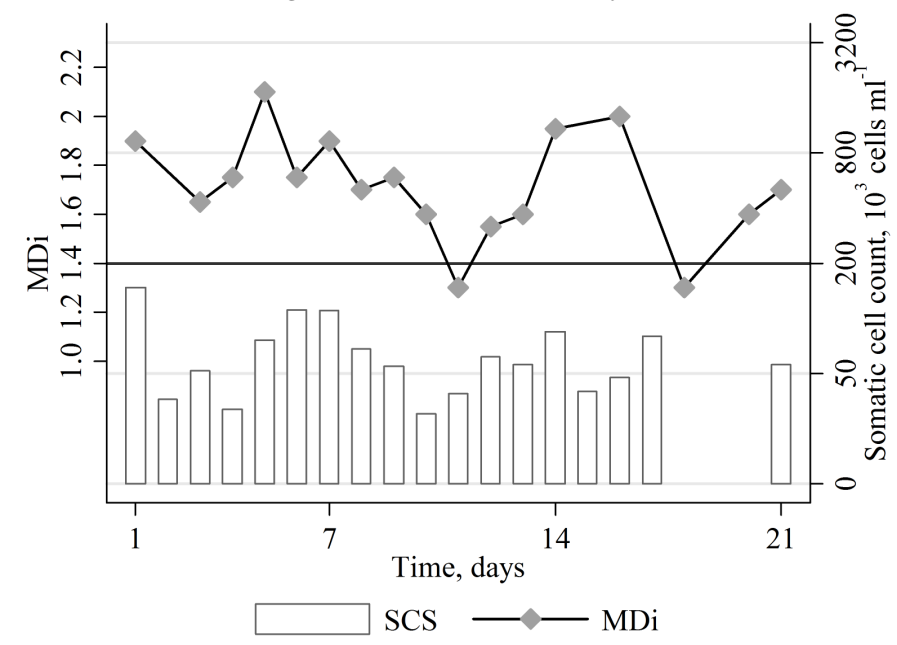

Fig. 3. MDi and somatic cell count of experimental cow No 7484

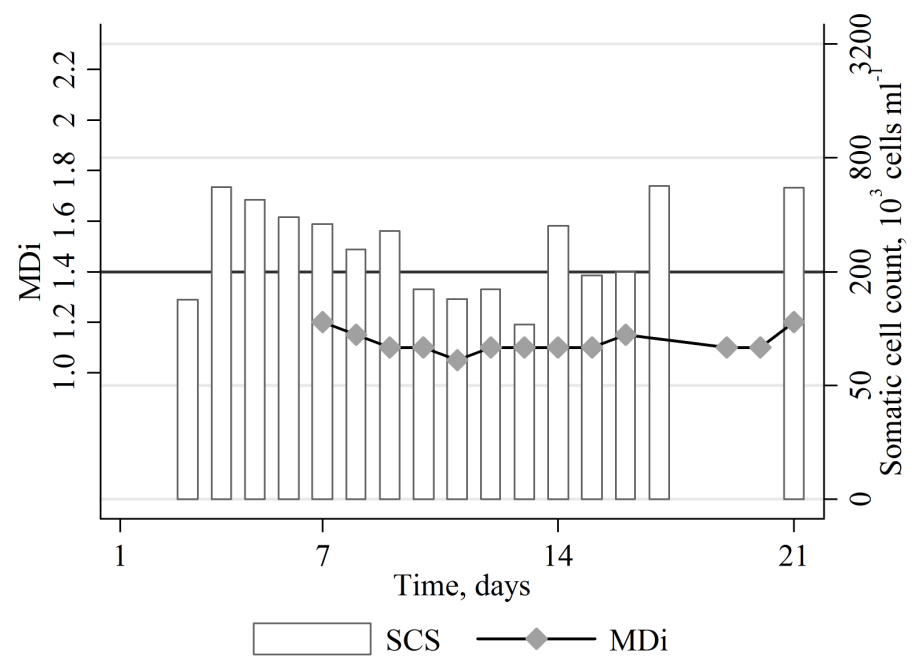

Fig. 4. MDi and somatic cell count of control cow No 7375 
The threshold values of MDi for automatic detection of abnormal milk were modeled using the $\mathrm{MDi}, \mathrm{SCC}$ and produced milk amount. It was found out that the total amount of diverted milk at the MDi threshold value of 2.0 would be $102 \mathrm{~kg}$ or $2.3 \%$ out of total produced milk ( $4387 \mathrm{~kg}$ ). Milk divert would be done at 9 milking sessions and theoretically estimated SCC of diverted milk would be around 422000 cells $\cdot \mathrm{ml}^{-1}$, and the bulk tank SCC would be around $155000 \mathrm{cells} \cdot \mathrm{ml}^{-1}$. From practical point of view, divert of abnormal milk helps keep control of the bulk tank milk SCC level below 300000 cells $\cdot \mathrm{ml}^{-1}$. Any lower threshold, for example 1.8, would increase the amount of diverted milk up to $265 \mathrm{~kg}$ ( $6 \%$ of all milk produced) with SCC equal to 360000 cells $\mathrm{ml}^{-1}$. However, the somatic cell count in the bulk tank milk would decrease to 148000 cells. $\mathrm{ml}^{-1}$, which would make little practical sense in comparison with 155000 cells $\cdot \mathrm{ml}^{-1}$.

\section{Conclusions}

1. The changes in the MDi and somatic cell count are not in parallel, and therefore MDi as the only indicator cannot be objectively used for detection of cows with a high somatic cell count. However, the increase of the MDi does not exclude association with the biological changes in the udder or throughout the animal body.

2. From the practical point of view using the MDi as a tool for abnormal milk detection the MDI threshold value of $\geq 2$ helps keep the SCC control of the bulk tank milk below 300000 cells $\cdot \mathrm{ml}^{-1}$.

\section{References}

1. Lusis I., Antane V., Laurs A. Effectiveness of somatic cell count determination in the milking robots. Proceedings of IX international scientific conference "Engineering for rural development" 27.-28.05.2010. Jelgava, 2010, pp. 112-116.

2. Lukas M., Reneau J.K., Wallace R., Hawkins D., Munoz-Zanzi C. A novel method of analyzing daily milk production and electrical conductivity to predict disease onset. Journal of Dairy Science, vol. 92, 2009, pp. 5964-5976.

3. Norberg E., Hogeveen H., Korsgaard I.R., Friggens N.C., Lovendahl P. Electrical conductivity of milk - ability to predict mastitis status. J. Dairy Sci. 87, 2004, pp. 1099-1107.

4. Kamphuis C., Dela Rue B., Mein G., Jago J. Development of protocols to evaluate in-line mastitis-detection systems. J. Dairy Sci. 96, 2013, pp. 4047-4058.

5. Pyorala S. Indicators of inflammation in the diagnosis of mastitis. Vet. Res., Vol. 34, No 5, 2003, pp. 575-578.

6. Schukken Y.H., Wilson D.J., Welcome F., Garrison-Tikofsky L., Gonzalez R.N. Monitoring udder health and milk quality using somatic cell counts. Veterinary Research, 34 5, 2003, pp. 579-596.

7. Forsback L., Lindmark-Mansson H., Andren A., Akerstedt M., Andree L.,Svennersten-Sjaunja. Day-to-day variation in milk yield and composition at the udder-quarter level. J.Dairy.Science, Vol. 93, 2010, pp. 3569-3577. 